\title{
2
}

\section{Heidegger e o fundamento}

Trata-se de dizer algo sobre a tentativa de pensar o ser sem levar em consideração a questão de uma fundamentação do ser a partir do ente. A tentativa de pensar o ser sem o ente impõe-se porque, de outra maneira, penso não haver possibilidade de abrirem-se propriamente os olhos para o ser daquilo que "é" ao redor do globo terrestre; nem se fale então de determinar, de maneira satisfatória, a relação do homem com aquilo que se denominou "ser". (Heidegger, Tempo e Ser)

Após a publicação de Ser e tempo (Sein und Zeit) em 1927, surge Sobre a Essência do Fundamento ${ }^{127}$ (Vom Wesen des Grundes) datado de 1929 - é a primeira vez que Heidegger escreve espe-

127 Sobre a Essência do Fundamento, cujo título do original alemão é Vom Wesen des Grund, foi publicado pela primeira vez, como volume suplementar, no Jahrbuch für Philosophie und phänomenologische Forschung, Halle: 1929, p. 71-100, por ocasião da comemoração dos setenta anos de Edmund Husserl. Em nosso trabalho, utilizaremos a Quinta edição com a Tradução e Notas de Ernildo Stein. São Paulo: Abril Cultural, 1973. (Os Pensadores), extraída do volume Wegmarken, Vittorio Klostermann, Frankfurt am Main 1967, p. 21-71, que contém anotações marginais do autor. 
cificamente sobre o tema do fundamento ${ }^{128}$. Neste mesmo ano é publicado Kant e o Problema da Metafísica (Kant und das Problem der Metaphysik) e ainda Que é Metafísica? (Was ist Metaphysik?). Isto nos leva a pensar que, ao mesmo tempo em que Heidegger estava envolvido com os estudos sobre a metafísica, mais precisamente, com o desenvolvimento do questão do ser, também estava atento para a questão do "fundamento", visto que não apenas cronologicamente essas obras se aproximam, como observa Stein, mas também as temáticas parecem girar em torno do problema central do pensamento do filósofo naquela época, a saber, a pergunta essencial sobre o sentido do $\operatorname{ser}^{129}$.

Podemos afirmar que a temática do fundamento perpassa toda a obra heideggeriana e não somente nos dois momentos em que o filósofo se dedica especialmente à análise do assunto: em Sobre a Essência do Fundamento e em O Princípio do Fundamento ${ }^{130}$ (Der Satz vom Grund, 1957), respectivamente, primeira e segunda fase de seu pensamento. O fundamento faz parte do empreendimento mais amplo de Heidegger, como ele mesmo declara no Prólogo dessa última obra. Como Daniel Panis,

(...) colocar originalmente a questão do ser, é colocar autenticamente a questão do Fundamento. E inversamente. Colocar

128 O termo Grund que se traduz por "fundamento", "princípio" ou "razão", na língua filosófica alemã refere-se tanto ao objeto do conhecimento como ao ser. É ao mesmo tempo "fundamento epistemológico" e "fundamento ontológico". Grund é o princípio único do ser e do conhecer. Cf. PUECH, Michel. Kant et la causalité. Paris: Vrin, 1990. p. 101.

129 A temática do fundamento é estudada quando Heidegger analisa a transcendência, no parágrafo 69 de Ser e tempo. Cf. STEIN, E. em sua Introdução ao Método Fenomenológico Heideggeriano. In: HEIDEGGER, M. Sobre a Essência do Fundamento. 5. ed. Tradução e Notas de Ernildo Stein. São Paulo: Abril Cultural, 1973. (Os Pensadores). p. 283.

${ }^{130}$ O Princípio de Fundamento, cujo título do original alemão é Der Satz vom Grund, contém treze lições de um curso proferido em 1955-1956 na Universidade de Fribourg-en-Brisgau e uma conferência proferida em 1956. Utilizaremos a tradução francesa Le Principe de Raison. Traduit de l'allemand par André Préau et Préface de Jean Beaufret. Paris: Gallimard, 1999. 
originalmente a questão do Ser é colocar a questão do Ser como Fundamento. Colocar originalmente a questão do Fundamento é colocar a questão do Fundamento enquanto Ser ${ }^{131}$.

Num sentido preciso, colocar a questão do ser é colocar a questão do fundamento que, no fundo, podemos dizer, é a abertura de novos caminhos que possibilitam pensar uma nova ética. Desde Ser e tempo, quando Heidegger pergunta pelo ser e esforça-se em "desconstruir" a metafísica, está também pondo em "xeque" os "códigos morais" das éticas tradicionais que têm suas raízes metafísicas. De que modo o faz? Mostrando que há um ethos (no sentido essencial da palavra), uma maneira de existir, de "habitar" chamada por ele de ser-aí, que não pode ser determinada por nenhum "princípio supremo": “(...) só o fato de estar entregue à sua própria responsabilidade o permite existir como o ente que é, ao existir na origem de seu poder-ser"132.

Ao questionar a metafísica tradicional com seu conceito de ser como "presença", e de tempo como tempo "presente"133, Heidegger questiona também o princípio das éticas infinitistas, segundo o qual todo agir humano obedece a máximas universais. Para ele, como demonstra Loparic em Ética e Finitude, o que essas éticas pretendem é eliminar a condição de finitude do homem, marcada pelo sofrimento, pelos desprazeres, pela efemeridade do prazer e transitoriedade do existir ${ }^{134}$. Neste sentido, ressalta Loparic, trata-se de uma ética que, a fim de lidar com a dor da finitude humana, define o agir como uma obediência, "no presente", a "paliativos" que tentam ser um sedativo para essa dor, ou promete a felicidade, pelo menos numa vida futura, no "ainda-não presente", a todo aquele que obedece a um dever absoluto ${ }^{135}$. Trata-se, enfim, de uma ética à qual está sobreposta a pergunta: que devo fazer para ser feliz? Ou: que posso esperar se eu fizer aquilo que me cabe ${ }^{136}$ ? Para o "filósofo da finitude",

${ }^{131}$ PANIS, Daniel. Il y a le "Il y a": L'Énigme de Heidegger. Bruxelles: Éditions OUSIA, 1993. p. 11.

${ }^{132}$ HEIDEGGER, M. Etre et Temps. p. 341.

${ }^{133}$ Cf. a seção 1.2.1 "A pergunta pelo ser no Primeiro Heidegger" no primeiro capítulo.

${ }^{134}$ LOPARIC, Z. Ética e Finitude. p. 51.

${ }^{135}$ Id. ibid. p. 52.

${ }^{136}$ Id. ibid. p. 32 e também p. 58. 
Quando se levantam perguntas sobre um dever, o ente que faz essas perguntas está suspenso entre ‘sim' e 'não', sendo perseguido pelo que não deve. Um ente que tem interesses fundamentais num dever, sabe de si como quem ainda-não-cumpriu, e questiona sobre aquilo que pode ser o seu dever. Esse aindanão de um cumprimento ainda indeterminado é testemunha de que um ente, cujo interesse se prende a um dever, é finito no seu próprio fundamento ${ }^{137}$.

Assim, prosseguiremos nossa investigação à luz da "desconstrução" heideggeriana do edifício metafísico. Tendo em mira a leitura de uma ética em Ser e tempo, objeto de nossa pesquisa, neste capítulo, analisaremos a "desconstrução" do tradicional princípio de fundamento. Embora possamos, eventualmente, fazer referência à obra da segunda fase, demorar-nos-emos particularmente no ensaio de 1929 (Sobre a Essência do Fundamento) visto que aprofunda algumas idéias postas por Heidegger em Ser e tempo, especialmente aquelas relacionadas à "mundanidade do mundo" e ao "cuidado". Mas, como o título já expressa, é também uma tentativa de analisar o fundamento do "ato de fundar", mostrando que a sua possibilidade está vinculada ao modo de ser do ser-aí, o Dasein, como um ente que é, em sua essência, transcendente ${ }^{138}$. Isso significa: um ente que "estáaí-no-mundo" implicado com o seu poder-ser, e este é o seu fundamento: o fato de ser "projeto-lançado", de ser o único responsável pelas possibilidades ontológicas de ser o ente que é.

Nesse sentido, Sobre a Essência do Fundamento, de certa forma, segue a construção heideggeriana de uma fenomenologia do existir humano cuja reflexão teve início em Ser e tempo. Mostraremos que, se há em Ser e tempo elementos originários de uma ética possível, eles estão longe do domínio objetivante da razão suficiente - princípio infinitista de causas primeiras, de certezas absolutas e verdades inquestionáveis, do padrão que dita tudo o que existe e tudo o que deveria existir.

${ }^{137}$ HEIDEGGER, M. Kant et le Problème de la Métaphysique. Paris: Gallimard, 1998. p. 273.

138 Cf. MORUJÃO, C. op. cit. p. 58. 


\subsection{A “DESCONSTRUC̣ÃO” DO PRINCÍPIO DE FUNDAMENTO}

"Soam incessantemente nos nossos ouvidos o princípio de razão: Nihil est sine ratione. Nada é sem razão"139. Heidegger assim se expressa na primeira lição do seu livro O Princípio de Fundamento, ressaltando que todo o nosso comportamento é regido pelo que diz o "princípio de razão", e sempre foi, sem que precisasse de uma formulação especial como princípio para nos orientar ${ }^{140}$. Ele então se pergunta, com ar de surpresa: por que foi preciso dois mil e trezentos anos para que o pensamento ocidental viesse a fazer essa descoberta e estabelecer esse simples princípio como Princípio (Grundsatz)? Por que precisou passar por esse "tempo de incubação" e por que foi um tempo tão longo ${ }^{141}$ ? Afinal, após mais de dois milênios, desde o início do filosofar com os gregos, até Leibniz, ninguém sentiu necessidade de expressar formalmente o princípio de razão! E por que isso não aconteceu junto com o surgimento da filosofia, já que era ela que detinha a tarefa da razão? E quando foi formulado, por que não causou perplexidade?

Comecemos, então, por situarmo-nos no contexto da discussão em torno da problemática do princípio de razão. Nossa investigação segue tão somente o fio condutor apontado por Heidegger em Sobre Essência do Fundamento, qual seja, o de que esse princípio possa fornecer um modo mais adequado de falar do fundamento. Neste caso, não é nossa intenção, aqui, aprofundar a história de tal princípio nem os pressupostos filosóficos a ele vinculados, o que nos obrigaria a um estudo exaustivo do diálogo permanente que Heidegger estabelece com outros pensadores além de Leibniz (com os filósofos gregos, Platão e Aristóteles, e ainda com Kant e Husserl, para citar alguns). Isso consequentemente nos faria desviar da temática que nos propusemos pesquisar: a possibilidade de uma ética na ontologia fundamental heideggeriana.

${ }^{139}$ HEIDEGGER, M. Le Principe de Raison. p. 44.

${ }^{140}$ Id. ibid. p. 45.

${ }^{141}$ Id. ibid. p. 46. 
Nossa questão é: como se caracteriza o agir humano na visão de Heidegger? O que "fundamenta" as ações humanas? Há uma "base" comum sobre a qual está assentado o existir do homem? Há algo que normatize os comportamentos, as relações humanas? Existe uma "verdade universal" que dirige o pensar e o agir do homem? São essas as questões que teremos como pano de fundo ao estudar, neste capítulo, o princípio de fundamento.

No ensaio Sobre a Essência do Fundamento, o tema do fundamento $^{142}$ é abordado por Heidegger tendo como objeto a pergunta pela sua essência ${ }^{143}$. A fim de tentar encontrar uma elucidação possível a essa questão, nosso Filósofo se lança à análise do principium rationis sufficienttis formulado explicitamente por Leibniz. Para nosso autor, o princípio de razão suficiente, por situar-se no âmbito da lógica, não se põe como a via mais adequada para abordar o problema da essência do fundamento. Heidegger acredita, no entanto, que uma discussão em torno desse princípio poderá apontar outra via, qual

${ }^{142}$ A palavra grega $\alpha \rho \chi \eta$ (archê) parece ter surgido na linguagem filosófica com Aristóteles, sendo traduzida para o latim como "principium". Em Metafísica, princípio é para Aristóteles o elemento primeiro, como o casco é para o navio e as fundações são para uma casa. Ainda em Metafísica, "o ponto de partida de conhecimento de uma coisa é também chamado princípio dessa coisa. (...) As causas são tomadas na acepção de princípios, porque todas as causas são princípios". ARISTOTE, Métaphysique, Livre $\Delta, 1013$ a, 3-17.

${ }^{143}$ É preciso que desde já esclareçamos o seguinte: no sentido em que Heidegger emprega, a palavra essência (Wesen) nada tem a ver com o caráter essencialista, qüididativo, da metafísica. Longe de qualquer referência ao tradicional par da oposição metafísica essência/existência, o Filósofo dá-lhe nova compreensão. No sentido fenomenológico, carregados de força verbal, Wesen passa a significar manifestação fenomenológica, acontecer, imperar, revelar-se; assim como Unwesen (não essência), frustrar e perturbar o acontecer, o imperar; assume a significação de "dissimulação do que de si se revela", ou seja, "ocultação fenomenológica". Temos então que "toda a problemática do fundamento é arrancada de sua perspectiva essencialista metafísica". Expressões como "essência do fundamento", "essência da verdade" devem ser tomadas em consideração nesse novo contexto: o da transcendência. Cf. STEIN, Ernildo em seu comentário da nota 12 em Sobre a Essência do Fundamento. p. 296. 
seja, a da transcendência ${ }^{144}$, como veremos.

Leibniz apresenta, pois, o problema do fundamento ${ }^{145}$ sob a forma do principium rationis sufficienttis. Segundo tal princípio, "nihil est sine ratione"; em alemão, nicthts ist ohne Grund, ou seja, nada é ou existe sem razão ${ }^{146}$. De outra forma: "omne ens habet rationem", que quer dizer: toda coisa que é, cada ente que é, qualquer ente que $e ́, e ́$ ou existe porque tem razão, fundamento ou causa em outro ente que, por sua vez, tem razão, fundamento ou causa em um outro ainda, obedecendo a uma cadeia sucessiva de entes fundados e fundantes que deságua em um outro ente considerado um "ente supremo", causa sui, para além do qual nada mais há. É o último (ou primeiro) ente que "presta contas" e "exige contas" do fundamento, como Heidegger se refere em A Constituição Onto-teo-lógica da

144 Cf. HEIDEGGER, M. Sobre a Essência do Fundamento. p. 295 e 296. Ver também BLANC, Mafalda Faria. O Fundamento em Heidegger. p. 54.

${ }^{145}$ O princípio de fundamento já era conhecido em toda a história da filosofia como o princípio de causalidade. Conforme Heidegger, a formulação do problema do fundamento foi posta pela primeira vez no século XVII por Leibniz, na forma abreviada do principium rationis sufficientis e somente no século XVIII, com Chr. A. Crusius (1743), em sua Dissertatio philosophica de usu et limitibus principii rationis determinantis vulgo sufficientis é que foi realizado pela primeira vez um estudo sobre o "Princípio da Razão". Em 1813, Schopenhauer também escreveu sua dissertação "Sobre a Quádrupla Raiz do Princípio da Razão Suficiente". Ainda foi alvo de interesse para Kant do início ao fim de sua carreira filosófica, sendo mais expressamente analisado em Crítica da Razão Pura (1781) e para Schelling com suas Investigações da Liberdade Humana e os Objetos com Ela em Conexão (1809). Cf. HEIDEGGER, M. Sobre a Essência do Fundamento. p. 295 e 296.

146 Em Leibniz, a expressão "princípio de razão" apresenta uma dificuldade. Não é o termo princípio que traduz "archê" mas a palavra "razão": nihil est sine ratione. O "princípio de razão" torna-se uma tautologia: "princípio de archê", "princípio de princípio". (Cf. ARISTOTE, Métaphysique, Livre $\Delta, 1013$ a, 3-17; e também: SCHÜRMANN, Reiner. Le Principe d'Anarchie. Heidegger et la question de l'agir. Paris: Éditions du Seuil, 1982. p. 115). Segundo Loparic, a palavra latina ratio pode ser traduzida como "fundamento", "razão" ou "causa", dando origem às expressões: princípio de fundamento, princípio de razão suficiente e princípio de causalidade. Cf. LOPARIC, Z. Ética e Finitude. p. 17. 
Metafísica ${ }^{147}$ ou, como salienta Reiner Schürmann, é uma espécie de “ 'suporte', precisamente, que reúne três características, de ser antes em posição (das schon Vorliegende), de ser por auto-posição (von sich her), e de servir de suposição (unter- und zugrunde liegen)"148.

Do ponto de vista heideggeriano, o tradicional princípio de razão, bem como os seus pressupostos filosóficos são questionáveis. Com a pergunta pela essência do fundamento, Heidegger pretende mostrar a insuficiência desses pressupostos filosóficos, todavia, não é a sua intenção "destruir" esse princípio. De fato, ele existe como essência do infinitismo metafísico em que

o fundar mesmo aparece (...) como algo que é e que assim por si mesmo exige, enquanto ente, a correspondente fundação pelo ente, quer dizer, a causação, e, na verdade, a causação pela causa suprema. (...) Porque o ser aparece como fundamento, o ente é o fundamentado; mas o ente supremo é o fundamentante no sentido da primeira causa. Pensa a metafísica o ente no que respeita seu fundamento, comum a cada ente enquanto tal, ela é lógica como onto-lógica. Pensa a metafísica o ente enquanto tal no todo, quer dizer, no que respeita o supremo (que é o) ente a que tudo fundamenta, ela é lógica como teo-lógica ${ }^{149}$.

O ser é pensado pela metafísica como o fundamento fundante de tudo o que há: o ser é do ente e o ente é do ser, ou de outra forma, o ser funda o ente e o ente é fundado pelo ser e, neste caso, a diferença entre eles fica impensada. Quando muito, é pensada num "plano ôntico", num plano hierárquico entre entes ou tipos de entes, como dissemos e bem ilustra Michel Haar: para ele, a diferença ontológica, que deve ser compreendida "horizontalmente", não é tematizada pela metafísica a não ser numa perspectiva "vertical”, segundo uma cadeia subordinativa entre um ente superior (forma, idéia, inteligível) e um ente inferior (matéria, devir, sensível), exemplifica, citando a versão

${ }^{147}$ Cf. HeIDEGGER, M. A Constituição Onto-teo-lógica da Metafísica. p. 393.

148 SCHÜRMANN, R. op.cit. p. 137.

149 HEIDEGGER, M. A Constituição Onto-teo-lógica da Metafísica. p. 398 e 399 . 
platônica ${ }^{150}$. São oposições que tendem a ser solucionadas ou "reconciliadas" dialeticamente: essência/existência, originário/derivado, transcendental/empírico, universal/particular, teórico/prático, alma/ corpo, razão/sensibilidade ... Em todo caso, é o mesmo "elemento superior", analisa ainda Michel Haar, que está em jogo, é ele que funda, que possui a "potência fundadora": o supra-sensível "funda" o sensível, em Platão, como o transcendental "funda" o empírico, em Kant ${ }^{151}$

É assim, para Heidegger, que o princípio de razão existe como a "declaração" mais concreta de que o ser foi esquecido. É exatamente nas bases deste princípio, esquecido do tempo e da finitude, que estão fundamentados todo o pensar e agir do homem ocidental.

Nosso filósofo põe à prova a noção tradicional do fundamento, o princípio de razão, desmonta-o, a fim de chegar a um modo mais originário de pensar que traga à compreensão a razão da razão (afinal, como afirma Panis, razão é também ente ${ }^{152}$ ), conferindo a ela um caráter transcendental. Em outras palavras, a "desconstrução" heideggeriana do princípio de fundamento da ontologia tradicional sobre a qual refletimos, vai na direção de mostrar que o existir humano não pode estar sedimentado em causas "racionais" (últimas ou primeiras), edificadoras das éticas infinitistas, mas em algo mais originário, em outro chão, naquele esquecido chão do "jazimento do ser", no dizer de Loparic ${ }^{153}$.

Assim, Heidegger inicia o seu pequeno tratado de 1929 mostrando que o "princípio de razão" é uma proposição que se enuncia

150 Para Michel Haar, a própria enumeração destas oposições demonstra a referência da linguagem aos esquemas da representação, daí a dificuldade de dizer o ser de outra forma senão pela boca da metafísica. (Cf. HAAR, Michel, La Fracture de l'Histoire. p. 101). Como Heidegger diz, "tem-se por mais acertado dizer que a linguagem está a serviço do pensamento em vez de: o pensamento como correspondência da linguagem". HEIDEGGER, M. Que é Isto - A Filosofia?. 5. ed. Tradução e notas de Ernildo Stein. São Paulo: Abril Cultural, 1973. p. 221. (Os Pensadores).

151 Cf. HAAR, M. La Fracture de l'Histoire. p. 101 e 102.

152 Cf. PANIS. Daniel. Il y a le "Il y a": p. 31.

153 Cf. LOPARIC, Zeljiko. Ética e Finitude. p. 29. 
sobre o ente na direção de sua razão, de seu fundamento: "nada é sem razão (fundamento) de ser", "todo ente tem uma razão (fundamento) de ser". No entanto, adverte-nos, a própria essência do fundamento não é posta em questão na proposição, ao contrário, é dada como evidente por si. Em outras palavras, o "princípio supremo" da razão não se inclui ao que ele próprio se propõe analisar ${ }^{154}$, mas reveste-se com o caráter de soberania intocável, de verdade universal. Vê-se, então, que a essência do fundamento não se confunde e muito menos se reduz à explicitação suficiente do princípio de razão, o que só comprova a necessidade de colocá-lo em discussão. É o que faz Heidegger.

Para Leibniz, o principium rationis sufficientis está estreitamente ligado à essência da verdade. Mais do que isso: origina-se da verdade. A verdade subsiste, por isso também subsiste o principium rationis ${ }^{155}$. Entendida por ele no sentido aristotélico, a verdade é "verdade da proposição" (Aussage-wahrheit), ou seja, a essência da verdade consiste na conexão entre sujeito e predicado. É nessa conexão que se encontra a sua validade universal. Dito de outro modo, a essência da verdade proposicional reside na "identidade", elaborada pelo juízo, que é estabelecida entre duas representações. Uma proposição só pode ser legítima se não implica nenhuma contradição. Requer, pois, sempre uma referência objetiva a algo, como fundamento a partir do qual essa "identidade" possa existir ${ }^{156}$.

Desse modo, Schürmann ressalta que o princípio de razão é tal como uma lei através da qual todas as coisas vêm ao pensamento. Trata-se de uma lei que visa fornecer provas: uma coisa existe verda-

${ }^{154}$ Cf. HEIDEGGER, M. Sobre a Essência do Fundamento. p. 297. Em O Princípio de Fundamento Heidegger também volta a chamar a atenção sobre o caráter enigmático do princípio de razão quando ele mesmo não é submetido à análise. Cf. HEIDEGGER, M. Le Principe de Raison. p. 49. Sobre isto ver ainda: PANIS, Daniel. Il y a le "Il y a". p. 34.

155 Cf. HEIDEGGER, M. Sobre a Essência da Verdade. p. 298.

${ }^{156}$ Certamente, é na interpretação do ser do ente como "presença" e do tempo como o "presente constante", constituído de sucessivos "agoras", que a metafísica encontra apoio para a sua noção de fundamento. Cf. a seção 1.2.1 "A pergunta pelo ser no Primeiro Heidegger" no primeiro capítulo. 
deiramente se ela se torna presente ao sujeito representante, se a sua causa pode ser demonstrável, explicável ${ }^{157}$. Isto significa que, para toda a metafísica tradicional e, portanto, também para Leibniz,

Verdade significa (...) acordo que somente é tal enquanto concordância com aquilo que na identidade se manifesta como unido. As 'verdades' - enunciações verdadeiras - recebem sua natureza por referência a algo em razão do qual podem ser acordos. Em cada verdade a união que separa é o que é, sempre em razão de..., isto é, como algo que se 'fundamenta'. Na verdade reside, por conseguinte, uma referência essencial a algo semelhante como "fundamento"158.

Vemos, portanto, que a verdade preconizada pela metafísica está no âmbito da lógica formal; é formulada enquanto a verdade do juízo, da união que nasce do acordo (Einstimmigkeit) entre um ente que é sujeito, e outro ente que é objeto. Um acordo entre o conhecimento e a coisa. Aí mora a sua essência e é nessa fonte que o tradicional princípio do fundamento se alimenta. Haveria, nesta perspectiva, um contrário da verdade, a não verdade, compreendida como a não concordância entre a representação e o objeto ${ }^{159}$. Sob esse prisma, agir conforme a verdade, significa exatamente "nos conformarmos com a coisa, tomarmos a coisa como norma. (...). Procurar estar em conformidade com a coisa significa tomá-la como norma de nosso julgar e de nosso dizer (...)"160.

É justamente essa acepção que Heidegger critica. Ele contesta o modo estreito imposto pela tradição de pensar a pergunta pelo fundamento na esfera da lógica. Tomando como guia esta relação fundamento-verdade lançada por Leibniz, afirma:

157 Cf. SCHÜRMANN, Reiner. Le Principe d'Anarchie. p. 136 e 137.

158 HEIDEGGER, M. Sobre a Essência do Fundamento. p. 298.

159 "Assim, a fórmula da essência da verdade (veritas est adaequatio intellectus et rei) adquire, para cada um e imediatamente, uma evidente validez. Sob o império da evidência deste conceito de essência da verdade mal e mal meditada em seus fundamentos essenciais, admite-se como igualmente evidente que a verdade tem um contrário e que há a não-verdade". HEIDEGGER, M. Sobre a Essência da Verdade. p. 332. 160 VATTIMO, Gianni. Introduction à Heidegger. p. 83 e 84. (Grifos do autor). 
Se (...) a essência do fundamento possui uma relação interna com a essência da verdade, então também o problema do fundamento somente pode residir lá onde a essência da verdade haure sua possibilidade interna, na essência da transcendência. A questão da essência do fundamento transforma-se no problema da transcendência ${ }^{161}$.

Por que Heidegger coloca o problema da verdade, do fundamento e da transcendência juntos, numa única questão? Quais são as relações entre esses elementos?

O que Heidegger quer dizer é que a verdade não é simplesmente a verdade da descoberta de sentenças verdadeiras ou falsas. No fenômeno da verdade não está em jogo o que pode ser verdadeiro ou não, mas antes, "a verdade da proposição está radicada numa verdade mais originária (desvelamento), na revelação antepredicativa do ente que podemos chamar de verdade ôntica"162. As proposições só são possíveis, os entes só se tornam acessíveis em si mesmos porque são radicados numa verdade originariamente fundante, denominada verdade ontológica. Essa é, portanto, condição transcendental de possibilidade de toda verdade ôntica ${ }^{163}$. Tal condição nada mais é do que a possibilidade do velamento-desvelamento do ser, portanto, do estabelecimento da diferença fundamental de ser e ente. É a partir dessa diferenciação ôntico-ontológica que Heidegger justifica a sua concepção da verdade:

Desvelamento do ser é, porém, sempre, verdade do ser do ente, seja este efetivamente real ou não. E vice-versa, no desvelamento do ente já sempre reside um desvelamento de seu ser. Verdade ôntica e ontológica sempre se referem, de maneira diferente, ao ente em seu ser e ao ser do ente. Elas fazem essen-

161 HEIDEGGER, M. Sobre a Essência do Fundamento. p. 301. (Grifos do autor).

162 HEIDEGGER, M. Sobre a Essência do Fundamento. p. 299.

163 "Desvelamento do ser é o que primeiramente possibilita o grau de revelação do ente. Este desvelamento como verdade sobre o ser é chamado verdade ontológica". Cf. HEIDEGGER, M. Sobre a Essência do Fundamento. p. 299. 
cialmente parte uma da outra em razão de sua relação com a diferença de ser e ente (diferença ontológica) ${ }^{164}$.

Nesse sentido originário, a verdade transcendental só pode ser verdade existencial ${ }^{165}$. De outra maneira, a essência do fundamento só pode ser compreendida na transcendência do Dasein ${ }^{166}$, enquanto ser-aí. Em outras palavras, só há verdade enquanto há ser-aí167: o aí (Da) é o "lugar" onde acontece o velamento e o desvelamento, o lugar em que se tem a questão da verdade ${ }^{168}$. Neste sentido, o aí pode ser compreendido como o "mundo"169, a estrutura unitária existencial, o "horizonte" a partir do qual o ser-aí transcende. Dessa forma, Rüdiger Safranski ressalta: “(...) o dasein humano não tem outro apoio [diríamos, fundamento] senão esse aí (da), que é seu"170.

164 HEIDEGGER, M. Sobre a Essência do Fundamento. p. 300.

165 STEIN, Ernildo. Seminário sobre a Verdade: Lições Preliminares sobre o Parágrafo 44 de Sein und Zeit. Petrópolis: Vozes, 1993. p. 21.

166 O termo Dasein é composto de duas palavras: Da e Sein. Literalmente significa "existência". Comumente traduzimos Da por ai (os franceses o traduzem por là). O aí traduz o Da como advérbio de lugar, porém, segundo BIEMEL, Walter, na terminologia heideggeriana o Da não exprime um simples "aí", um simples lugar determinado no espaço, mas é a abertura do ser-aí, o espaço em que todos os entes se manifestam ou, como o próprio Heidegger explica em Introdução à Metafísica, "o Da é o espaço aberto por a irrupção do homem"; "por ser aberto, torna possível o encontro dos entes". Mas, esta abertura do ser-aí só é possível porque ele mantém uma relação essencial com o Ser (Sein). "Existir é ser o portador da abertura do Ser. É o Ser que dá ao Dasein a zona de desvelamento (...). A maneira pela qual esta abertura se revela não depende em primeiro lugar do Dasein, mas do Ser ele-mesmo". (Cf. WALTER, Biemel. Le Concept de Monde chez Heidegger. Paris, Vrin, 1950. p. 82 e 84).

167 STEIN, Ernildo. Melancolia. Ensaios sobre a finitude no pensamento ocidental. Porto Alegre: Movimento, 1976. p. 76.

168 STEIN, Ernildo. Seminário sobre a Verdade. p. 21.

169 "Mundo constitui a estrutura unitária da transcendência; enquanto dela faz parte, o conceito de mundo é um conceito transcendental". Cf. HEIDEGGER, M. Sobre a Essência do Fundamento. p. 303.

170 SAFRANSKI, R. Heidegger: um mestre da Alemanha entre o bem e o mal. Trad. de Lya Luft. Apresentação de Ernildo Stein. São Paulo: Geração Editorial, 2000. p. 187. 
Ser transcendente como uma constituição ontologicamente fundamental, significa que faz parte do modo de ser mais próprio do ser-aí existir como ser-no-mundo, revelar o ente em seu ser ao mesmo tempo em que "se" revela. Mas isso não é algo que lhe ocorre de vez em quando, algumas vezes sim, outras não, quando se "quer", quando "dá na telha". Como um modo de ser fundado ontologicamente, essa verdade transcendente acontece antes de qualquer comportamento ${ }^{171}$, é anterior a qualquer consciência "ôntica", a qualquer faculdade intelectiva, volitiva, ou psíquica, porque a transcendentalidade da qual fala Heidegger é "ligada ao mundo prático, ligada ao Dasein e, portanto, não mais no caráter da subjetividade"172. A verdade transcendente nada tem a ver com teoria do conhecimento; a transcendência heideggeriana não é aquela "subjetiva", aquela que leva o sujeito, frente ao objeto, a "ultrapassar" um obstáculo ou um fosso e, enfim, obter conhecimento dele ${ }^{173}$.

Sob este ponto de vista, ofundamento não remete mais a causas ou razões supremas, mas à descoberta de um acontecer originário ligado à transcendência, ou mais precisamente, como dissemos, à existência, ao ser-aí. A verdade que discutimos aqui é a verdade ontológica, a verdade como desvelamento.

Surge-nos, então, uma interrogação: podemos pensar que existe, no âmbito da transcendência, uma relação entre o fundamento e o ser? Como se daria essa relação?

\subsection{O DASEIN COMO O FUNDAMENTO PRIMORDIAL}

Dizer que a verdade é verdade do desvelamento é dizer que a verdade mora no Dasein, é dizer, de outro modo, que ele é o fundamento. E mais: ofundamento primordial. De fato, em Ser e tempo, Heidegger demonstrou o privilegiamento do Dasein, único ente que

${ }^{171}$ Cf. HEIDEGGER, M. Sobre a Essência do Fundamento. p. 302.

172 STEIN, Ernildo. Seminário sobre a Verdade. p. 22.

${ }^{173}$ Cf. HEIDEGGER, M. Sobre a Essência do Fundamento p. 302 e também Ser e tempo, Parágrafo 13. 
mantém uma "relação" essencial com o ser, é alguém que, originariamente, é abertura ao ser ${ }^{174}$. Isto não significa outra coisa senão que é o Dasein que abre um horizonte em que todos os entes se tornam acessíveis, em que todos os entes sãofundados. Porque pensamos na direção da transcendência do Dasein é que pensamos haver uma relação entre o fundamento e o ser.

Levando em consideração essa forma de pensar, o princípio de razão suficiente, enquanto tem a sua validade universal no ente subsistente, ou seja, enquanto está baseado em algo como "simples presença", deve, antes, fazer-se remontar ao Dasein ${ }^{175}$. Como é salientado por Vattimo, "Se os entes vêm ao ser enquanto se situam no mundo como projeto aberto e instituído pelo Dasein, a validade do princípio de razão suficiente deverá também ela ser referida ao ser-aí que institui o mundo em que o ente aparece"176. Continua ele: "O Dasein, enquanto projeto lançado, tem já uma compreensão do ser do ente, compreensão que se articula num discurso (o discurso é um existencial) em que os entes estão concatenados entre si na forma de justificação ou fundação"177. É assim que, se o princípio de razão suficiente existe: existe porque o fundamento pertence à essência do ser, "porque ser (não ente) somente se dá na transcendência como o fundar situado que projeta o mundo"178, ou melhor dizendo, existe, porque existe o Dasein.

Eis a tese que Heidegger defende em Sobre a Essência do Fundamento: o ser-aí é o "verdadeiro fundamento". Mas, obviamente, e isto já deve ter ficado claro, não estamos falando daquele "fundamento" advogado pela metafísica no sentido de ser uma "simples presença" para além da qual nada se encontra e da qual tudo depende. Não se trata de uma espécie de "plataforma", de uma "base" ou, como diz Vattimo, de algo que primeiramente é e depois projete o mundo. O ser-aí é projeto e, como projeto, não poderia ser redutível a coisa al-

174 Cf. ã seção 3.2 "A finitude do ser e do Dasein" no Capítulo Terceiro.

175 VATTIMO, Gianni. Introduction à Heidegger. Traduit de l'italien par Jacques Rolland. Paris: Les Éditions du Cerf, 1985. p. 67.

${ }^{176}$ Id. ibid. p. 67.

${ }^{177}$ Id. ibid. p. 67. (Grifos do autor).

178 HEIDEGGER, M. Sobre a Essência do Fundamento. p. 322. 
guma, não poderia ser "simples presença", jamais poderia ser "fundamento último" nem nunca poderia ser "fundado"179. Por ser um ente que essencialmente é "projetante" ou, em outras palavras, por ser um ente, por natureza, transcendente, abre todo o horizonte de fundação. Como assinala Loparic,

enquanto projeto ou existência no sentido estrito, o estar-aí 'deixa estar', ele institui (stiftet) as possibilidades de manifestação do ente no seu todo (inclusive de si mesmo como ente concreto). Nesse sentido, ele é o fundamento soberano de toda possibilidade e de todo sentido (do a-fim-de-que, das Worumwillen) $)^{180}$.

Para Heidegger, então, Fundar é algo inteiramente diverso de como é entendido tradicionalmente o termo Grund. Em Sobre a Essência do Fundamento, fundar significa primeiramente, Gründen, isto é, a ação de fundar, erigir, abrir, projetar, instituir (Stiften) a possibilidade de que os entes se manifestem em seu ser, de que eles sejam. À medida em que o ser-aí como ser-no-mundo institui a possibilidade de que os entes existam como tais, ele é, de alguma forma, determinado pelas coisas que transcende, determinado por aquilo que ele ultra-passa, visto que, em sua transcendência, o ser-aí já se encontra sempre em-meio-ao ente ${ }^{181}$, no modo de ocupação e, assim, "toma por base" o próprio ente. Eis, então, que fundar significa, em segundo lugar, enraizar-se, "tomar-chão" (Boden-nehmen), ser ocupado pelo ente. Contudo, a secundariedade desse modo de fundar de maneira alguma decorre do primeiro, mas ambos se dão simultaneamente, uma vez que,

${ }^{179} C f$. VATTIMO, G. Introduction à Heidegger. p. 68.

${ }^{180}$ LOPARIC, Z. Ética e Finitude. p. 18. (Grifos do autor).

181 "Enquanto assim situado, o ser-aí é ocupado pelo ente de tal maneira que, pertencendo ao ente, é por ele perpassado pela disposição. Transcendência significa projeto de mundo, mas de maneira tal que aquele que projeta já é também perpassado pela disposição por obra do ente, que ele ultrapassa". HEIDEGGER, M. Sobre a Essência do Fundamento. p. 318. (grifos do autor). 
ao tomar um solo para erigir, solo esse que, ao mesmo tempo lhe é dado sob a forma daquilo 'a partir de onde' o erigir se torna possível, o Dasein humano configura e projeta um mundo, descobre-se a si mesmo como projeto-de-mundo e como transcendência ${ }^{182}$.

Em outra palavras, é somente pelo "enraizamento" na existência que qualquer coisa pode vir a "nascer"; trata-se de um fundo que possibilita (e não "causa") o projeto. Como ressalta Carlos Morujão em seu livro Verdade e Liberdade em Martin Heidegger, "É à facticidade da nossa existência mundana que o Ser aparece sob a forma de fundamento, ou seja, como aquilo sobre o que todo o nosso comportamento se revela capaz de erigir"183. Para Heidegger, "o ser-aí funda (erige) mundo apenas enquanto se autofunda em meio ao ente"184.

O fundar que erige antecipa, como projeto de mundo, possibilidades de existência. Existir significa sempre: situado em meio ao ente, comportar-se em face dele - do ente que não possui o caráter do ser aí, de si mesmo e de seu semelhante - de tal maneira que neste comportamento situado sempre esteja em mira o poder-ser do ser-aí. No projeto de mundo é dado um excesso de possível, em vista do qual e no ser perpassado pelo imperar do ente (real), que de todos os lados nos cerca no sentimento de situação, brota o porquêt ${ }^{185}$.

Assim, esses dois modos de fundar formam uma unidade transcendental que possibilita a revelação do ente em si mesmo, isto é, a verdade ôntica, ao constituir um terceiro modo de fundar: o fundar como fundamentar (Begründen), como legitimar, no sentido de assegurar um fundamento, uma causa, uma razão de ser - causa sive ratio - para tudo o que é ${ }^{186}$.

${ }^{182}$ MORUJÃO, C. op. cit. p.65

${ }^{183}$ Id. ibid. p. 64.

${ }^{184}$ HEIDEGGER, M. Sobre a Essência do Fundamento. p. 319.

${ }^{185}$ Id. ibid. p. 320.

${ }^{186}$ Cf. PANIS, D. Il y a "Le Il y A". p. 117. Heidegger articula esses três modos de fundar com o fenômeno originário da "temporalidade eks-tática" do ser-aí: o ser-aí abre um horizonte em que todos os entes são fundados porque se constitui como ente que é sempre já-lançado numa situação 
Heidegger não fala aqui de um "fundamentar" no sentido de apresentar logicamente as proposições ôntico-teoréticas, umas conexadas às outras, mas trata-se de um fundamentar que encerra em si uma significação fundamentalmente originária: a busca pela possibilidade transcendental de todo por que em geral ${ }^{187}$, isto é, a condição possibilitante de toda pergunta pelas razões ou causas das coisas em geral. Este "fundamentar" transcendental que legitima a revelação do ente em si mesmo, isto é, do ente que ele é e como o é, não é outra coisa senão a radicação da verdade ontológica a que nos referimos anteriormente:

Podemos então dizer que o erigir, o tomar-chão e o legitimar constituem o modo de existência do ser-aí como fundamento ${ }^{188}$. Enquanto transcendência, ou seja, existindo como projeto-lançado e estando ocupado pelo ente, o ser-aí o institui, e o faz interrogando-o em seus porquês: por que há alguma coisa ou tudo e não antes o nada? ${ }^{189}$ Por que isso e não aquilo? Por que assim e não de outra ma-

(passado), decaído junto-dos entes (presente) e determinado fundamentalmente por seu ser-adiante-de-si (futuro). Sobre isso, ver: BIRAULT, H. Heidegger et l'Expérience de la Pensée. Paris: Gallimard, 1986. p. 419. Ver também no terceiro capítulo, nota n. 117.

${ }^{187}$ HEIDEGGER, M. Sobre a Essência do Fundamento. p. 320.

${ }^{188}$ Cf. LOPARIC, Z. Ética e Finitude. p. 20.

189 Segundo Henri Birault, essa questão fundamental da filosofia pode ser lida de duas maneiras: pode ser orientada pela preocupação metafísica, neste caso, a ênfase está em "alguma coisa", como o faz Leibniz; ou pode ser uma leitura transcendental ou existencial, como é realizada por Heidegger e aqui o acento está sobre o "há". Birault explica: "No primeiro caso, a questão se desenvolve a partir e em proveito de um ente supremo que os filósofos consentem chamar de Deus conforme o uso popular. No segundo caso ao contrário, a questão se desenvolve em favor do há ele mesmo por meio de uma 'redução' ou de um 'colocar entre parênteses' tudo isto que é de uma maneira ou de outra, compreendido como ser supremo. No primeiro caso, a fórmula final 'e não antes o nada' tem a aparência de um complemento inútil ou de uma beleza de retórica. No segundo, ao contrário, ela é o princípio de onde brota a questão mesma. No primeiro caso, o por quê? tem ainda uma significação causal e significa a causa de que, em vista de que. No segundo, ele perde esta significação e se perde ele mesmo para ceder o lugar ao como? (...)". BIRAULT, H. 
neira? Segundo ressalta Heidegger, tal legitimação é, no entanto, "nula" (nichtig), uma vez que, enquanto projeto-lançado o ser-aí "é em si mesmo essencialmente um nada", pois, implicado com suas escolhas, ele estará sempre assumindo uma possibilidade e terá que suportar deixar outras para trás ${ }^{190}$. Mas é assim que ele existe, porque é um ente que vive a sua transcendência. Em sua Preleção de 1929, ele diz:

Se o ser-aí, nas raízes de sua essência, não exercesse o ato de transcender, e isto expressamos agora dizendo: se o ser-aí não estivesse suspenso previamente dentro do nada, ele jamais poderia entrar em relação com o ente, e portanto, também não consigo mesmo. Sem a originária revelação do nada não há sersi-mesmo, nem liberdade. ${ }^{191}$

É por isso, pois, que o "fundar" como Heidegger o entende, radicado na transcendência, deve ser entendido em sua relação originária com a liberdade ${ }^{192}$. A possibilidade do fundamento em geral está no exercício da liberdade do ser-aí. A liberdade, diz-nos Heidegger, é liberdade para o fundamento. Diríamos que o fundar, a transcendência e a liberdade são, de modo peculiar, inseparáveis. Trata-se de um Dasein que, por estar lançado no mundo como projeto, é livre poder-ser entre os entes ${ }^{193}$; é entregue à sua liberdade para fundar, para "dar razão" às coisas. Aí, então, reside - na liberdade finita do Dasein - a ação de fundar, explicitada por Heidegger em Sobre a Essência do Fundamento, e não em um "ser objetivo" que se impõe a "dar razão" a tudo o que existe ${ }^{194}$; ou, em outras palavras, que possa pretender assegurar "garantias" para o agir e o pensar.

Mas, por que a liberdade é "finita"? Parece ser uma pergunta sem nexo se tivermos em mente a definição de liberdade como propriedade do homem, cujo uso se associa ao "livre arbítrio"195, como

Heidegger et l'expérience de la pensée. Paris: Gallimard, 1978. p. 415.

190 HEIDEGGER, M. Être et Temps. p. 342.

191 HEIDEGGER, M. Que é Metafísica?. p. 239.

${ }^{192}$ Cf. HEIDEGGER, M. Sobre a Essência do Fundamento. p. 318.

193 Cf. HEIDEGGER, M. Sobre a Essência do Fundamento. p. 323

194 Cf. MORUJÃO, Carlos. Verdade e liberdade em Martin Heidegger. p. 64.

${ }^{195}$ Cf. HEIDEGGER, M. Sobre a Essência da Verdade. p. 337. 
"fazer o que se quer", como aquilo que é inerente ao sujeito, portanto, uma espécie de causalidade: faço isto porque quero/espero aquilo, ou vice-versa, quero/espero aquilo então faço isto. Ou seja, a liberdade encarada como "espontaneidade", ou seja, uma espécie particular de causalidade, um começar-por-si-mesmo, mais para trás não reside uma causa determinante ${ }^{196}$.

Essa noção "substancialista" da liberdade é contestada por Heidegger, mas não vamos aqui discuti-la, pois nos exigiria mais tempo do que dispomos. Interessa-nos a liberdade no sentido entendido por nosso Filósofo, aquela conquistada a partir da transcendência ${ }^{197}$, aquela que se refere à "capacidade" que o ser humano tem de transcender $^{198}$. A liberdade, para Heidegger, não depende da vontade empírica, como explicita Jean-Luc Marion, "não é uma coisa possível, mas mais radicalmente, é o possível por excelência, na medida em que ela abre o horizonte mesmo de todos os possíveis" ${ }^{199}$. É neste sentido e não em outro que dizemos que a liberdade é finita: porque o projeto, diz Heidegger, constitui em si mesmo mais possibilidades do que aquelas que o ser-aí é capaz de assumir:

(...) O projeto de possibilidades é, segundo sua essência, sempre mais rico que a posse que repousa naquele que projeta. Mas uma tal posse é própria do ser-aí, porque se encontra situado, como projetante, em meio ao ente. Com isto já estão subtraídas ao ser-aí certas outras possibilidades - e isto simplesmente através de sua própria facticidade ${ }^{200}$.

É isto o que Loparic quer destacar ao afirmar que "a insuperável bifurcação em existencialidade e facticidade só pode oferecer uma legitimação finita". Que quer dizer isso? Quer dizer que enquanto ser-

\footnotetext{
196 Id. ibid. p. 317.

197 Id. ibid. p. 317.

198 A propósito, ver a nota explicativa no. 67 de E. Stein. In: HEIDEGGER, M. Sobre a Essência do Fundamento. p. 317.

199 MARION, Jean-Luc. "Une Nouvelle Morale Provisoire: la liberté d'être libre". In: BRUAIRE, Claude (Org.). La Morale: sagesse et salut. Paris: Fayard, 1981. p. 139.

200 HEIDEGGER, M. Sobre a Essência do fundamento. p. 319.
} 
no-mundo, implicado com as possibilidades "mundanas", ou seja, realizáveis no mundo, o ser-aí é precisamente um fundamento nulo ${ }^{201}$. Situado como liberdade para poder-ser, o ser-aí é um projeto já ultrapassado, transcendido pela possibilidade de não-mais-ser-ai, um poder-ser nadificado pela única possibilidade que não pode ser nadificada: a de ser-para-o-fim ${ }^{202}$. Assim é que o ser-aí, em seu ser livre para fundar, em sua transcendência fundante, é fundamento, Grund, mas apenas como Abgrund, como abismo, como ausência de fundamento.

Portanto, para Heidegger, a finitude, desvelada na transcendência como liberdade para o fundamento ${ }^{203}$, funda o existir humano; "é a marca definitiva de todo ser e agir do homem. É a sua situação. (...) ela integra e unifica toda a sua experiência"204.

201 "O projeto não é somente determinado pelo nada de ser-fundamento, porque ele é sempre lançado, ao contrário, como projeto ele é essencialmente nada". HEIDEGGER, M. Etre et Temps. p. 342.

202 Cf. LOPARIC. Ética e Finitude. p. 21. Loparic faz ver que "com Ser e tempo, pela primeira vez na história da filosofia ocidental, o pensamento do não-ser e do não-agir passa a determinar o horizonte do pensamento do ser e do agir" e isso é fundamental para compreendermos a concepção heideggeriana do existir humano.

203 Cf. HEIDEGGER, M. Sobre a Essência do fundamento. p. 323.

204 STEIN, E. Melancolia: Ensaios sobre a finitude no pensamento ocidental. p. 71 . 
